\title{
La prensa gratuita en España: análisis morfológico comparativo de las publicaciones 20 Minutos, Metro, Qué! y ADN
}

\author{
Fernando Sabés Turmo \\ Profesor de Periodismo. Universidad Autónoma de Barcelona
}

Resumen:

El afianzamiento de la prensa gratuita en España es un hecho. Destacan cuatro cabeceras que reparten ejemplares en las principales ciudades del país: 20 Minutos, Metro, Qué! y ADN. Estas propuestas han cambiado de forma sustancial la estructura del sistema de la prensa diaria española y han popularizado una nueva forma de presentar los contenidos de la prensa escrita. En el artículo se pretende hacer un repaso a las características formales aplicadas por estas cuatro cabeceras que son las de referencia en la consolidación de este fenómeno en el Estado. En concreto, se abordan aspectos morfológicos como sus dimensiones, maqueta, extensión y orden de las secciones, tipografía, color y uso de la imagen, entre otros elementos, para conocer algo más de las claves del éxito de este modelo de prensa.

Palabras clave:

Prensa gratuita, España, análisis formal, éxito del modelo

Abstract:

Free press is fully established in Spain. There are four main papers in the country's major cities: 20 Minutos, Metro, Qué! and AND. These have substantially changed the structural system of daily press in Spain. This paper will try and offer an overview of the aforementioned papers and their formats. Special attention will be paid to size, extension and sequencing; typography, colour and use of image, so as to delve into the keys for success of this kind of press.

Keywords:

Free press, Spain, formal analysis, model success 


\section{Introducción ${ }^{1}$}

El sector de la prensa diaria en España está en un momento de profundos cambios. La consolidación de los diarios generalistas gratuitos², cuyos máximos exponentes son las cabeceras Metro, 20 Minutos, Qué! y ADN, ha hecho que los formatos de pago tengan también que apostar por modificaciones. En este sentido, en los últimos meses El País y La Vanguardia han acometido estas remodelaciones que los han acercado estéticamente a los gratuitos para competir en un mercado cada vez más saturado por una oferta muy dispar.

Sin ir más lejos, además de los gratuitos, los diarios tradicionales españoles tienen un nuevo competidor que se sitúa entre ambas propuestas, el rotativo Público, editado por Mediapublic ${ }^{3}$, que apareció por primera vez en los quioscos el 26 de septiembre de 2007. Aunque sea de pago, con una política de precios bajos está intentando captar a aquellos lectores que se han habituado a la prensa a través de los gratuitos.

Parece pues que esa prensa gratuita que se reparte en las principales ciudades españolas ha roto con cierto inmovilismo que siempre había caracterizado este medio de comunicación y que ha provocado, entre otros aspectos, prácticamente generalizar el consumo de este soporte entre los ciudadanos.

El objetivo de este trabajo es estudiar las propuestas morfológicas que plantean estas cuatro publicaciones con el fin de llegar a un público masivo. El trabajo se enmarca dentro de un proyecto global de ir analizando los cambios en los formatos que se van aplicando a la prensa diaria en España, tanto de pago como gratuita.

\section{Objeto de estudio}

El trabajo se centrará en la propuesta semanal impresa de lunes a viernes de las cuatro publicaciones (20 Minutos, Metro, Qué! y ADN) del 17 al 21 de diciembre de 2007, excluyendo de la muestra seleccionada los suplementos extraordinarios y las ediciones digitales. En todos los casos, se ha escogido la propuesta distribuida en Barcelona. Estas cuatro cabeceras reúnen a prácticamente la mitad de los lectores de la prensa

1 Este artículo se enmarca dentro de una línea de investigación en la que trabaja el autor de análisis de los nuevos formatos de la prensa en España.

2 El fenómeno de la prensa gratuita no es nuevo en España, si bien hasta la aparición de estas grandes cabeceras, estas publicaciones eran muy locales, temáticamente especializadas, básicamente publicitarias o vinculadas a instituciones, en su mayoría. En este sentido, estas cuatro cabeceras, de distribución estatal y ámbito informativo generalista, han supuesto una verdadera innovación.

3 Además de Mediapublic, otras 28 empresas relacionadas con el mundo de la comunicación forman parte del grupo Mediapro. Los servicios que ofrecen alcanzan todos los ámbitos de la comunicación, desde la producción de contenidos de audio y vídeo para televisión, radio, cine e Internet, hasta el alquiler de unidades móviles para cubrir eventos, la comercialización de derechos de acontecimientos deportivos o la distribución de material audiovisual, entre otros. 
diaria en España (48,52\%), según datos del Tercer Año Móvil de 2007 del Estudio General de Medios (EGM)4. El 50,81\% de sus lectores son hombres, mientras que el $49,17 \%$, mujeres.

Por edades, hay que indicar que los grupos más numerosos son de 25 a 34 y 35 a 44 años (23,1\% y 22,55\%, respectivamente), seguidos de los de 45 a 54 (16,76\%), de los de 55 a 64 (10,55\%), de los de 20 a 24 (10,47\%), de los de 65 y más $(10,27 \%)$ y de los de 14 a 19 (6,27\%).

Asimismo, prácticamente la mitad de los lectores son de clase media-media (48,97\%), aunque también destacan los de media-baja (22,65\%). Completan los porcentajes los grupos media-alta $(16,71 \%)$, alta $(10,42 \%)$ y baja $(1,22 \%)$.

Por último, en cuanto al hábitat, hay que destacar que la mayor parte de los lectores se concentra en las ciudades que son principalmente los núcleos donde se reparten estas cabeceras. Se dividen de la siguiente forma: capitales (59,2\%), de 50.000 a 500.000 habitantes (23,96\%), de 10.000 a 50.000 (12,75\%), de 2.000 a $10.000(3,45 \%)$ y de menos de $2.000(0,64 \%)$.

\subsubsection{Minutos}

20 Minutos apareció en España el 3 de febrero de 2000 con su edición en Madrid, aunque poco tiempo después empezó a distribuirse también en Barcelona. Actualmente, se reparte en A Coruña, Albacete, Algeciras, Alicante, Almería, Ávila, Badajoz, Barcelona, Bilbao, Burgos, Cáceres, Cádiz, Cartagena, Castellón, Ceuta, Ciudad Real, Córdoba, Cuenca, Elche, Gijón, Girona, Granada, Guadalajara, Huelva, Huesca, Jaén, Jerez, Las Palmas, León, Logroño, Lleida, Lugo, Madrid, Málaga, Marbella, Melilla, Murcia, Ourense, Oviedo, Palencia, Palma, Pamplona, Pontevedra, Salamanca, San Sebastián, Santander, Santiago, Segovia, Sevilla, Soria, Tarragona, Tenerife, Teruel, Toledo, Valencia, Valladolid, Vigo, Vitoria, Zamora y Zaragoza ${ }^{5}$.

Depende de la empresa Multiprensa y Más S.L., fundada en Madrid en 1999. Su accionista mayoritario es 20 Min Holding, líder en los mercados de prensa diaria gratuita de calidad en Suiza y Francia. El accionista principal de 20 Min Holding es Schibsted, un grupo de comunicación de origen noruego fundado en 1839 y que tiene una fuerte presencia en Noruega, Suecia, Dinamarca, Suiza, Estonia, Finlandia, Francia y España, donde es propietario de diarios de pago y gratuitos, televisiones, radios y multimedia, entre otros.

\footnotetext{
4 El Estudio General de Medios (EGM) es un estudio multimedia, es decir, analiza el comportamiento de cada individuo respecto a los distintos medios (entre ellos la prensa) y ofrece datos en tres oleadas anuales.

5 Los datos fueron actualizados el 17 de diciembre de 2007, a través de la página web del medio (http: www.20minutos.es)
} 
En cuanto a sus lectores, según datos del Tercer Año Móvil 2007 del Estudio General de Medios (EGM), es el diario más leído en todo el país con un total de 2.507.000, superando al resto de cabeceras gratuitas y también a $E l$ País (2.234.000) y al deportivo Marca (2.379.000), que son las dos principales publicaciones de pago. Reúne al 16\% de los lectores de la prensa diaria española y al 32,97\% del total de lectores de los cuatro gratuitos analizados.

\subsection{Metro Directo}

Pertenece al Grupo Metro International S.A, en el que se integran las 70 ediciones que se reparten en 20 países y se escriben en 18 idiomas, tanto en Europa, América y Asia ${ }^{6}$.

En España, inició su andadura en marzo de 2001 con la publicación Metro Directe-Barcelona llegando a Madrid en agosto del mismo año. Actualmente dispone de 16 ediciones: Andalucía, Aragón, Asturias, Baleares, Canarias, Cantabria, Comunidad Valenciana, Castilla La Mancha, Castilla León, Cataluña, País Vasco, Extremadura, Galicia, Madrid, Navarra y La Rioja.

Metro Directo cuenta con 1.721.000 lectores cada día, un dato que supone el 10,97\% del total de personas que revisan la prensa diaria en España y el 22,64\% de los cuatro principales gratuitos.

\subsection{Qué!}

El gratuito Qué! apareció en los quioscos el 18 de enero de 2005 impulsado por el grupo Recoletos. Los cambios posteriores en este conglomerado llevaron a que Qué! estuviera controlado por Factoría de Contenidos y el Grupo Godó, aunque finalmente en el verano de 2007 se concretó la compra del rotativo por el grupo Vocento. Qué! es un periódico con 13 ediciones (Madrid, Barcelona, Bilbao, Sevilla, Valencia, A Coruña, Vigo, Asturias, Mallorca, Alicante, Murcia, Málaga y Zaragoza) ${ }^{7}$.

En cuanto al número de lectores, es el segundo de los gratuitos por detrás de 20 Minutos con 1.955.000 diarios, es decir, un 12,48\% de los lectores de diarios en España y un 25,72\% de los cuatro gratuitos estudiados en este trabajo.

\section{4. $A D N$}

$A D N$ es la más joven de las principales apuestas de prensa diaria gratuita que tiene una presencia amplia en España. Nació el 1 de marzo de 2006 y está publicado por la sociedad Editorial Página Cero SA, en la que

\footnotetext{
6 Los datos fueron actualizados el 17 de diciembre de 2007, a través de la página web del diario (http//www.diariometro.es)

7 Los datos fueron actualizados el 17 de diciembre de 2007, a través de la página web del medio (http:// www.quediario.com/)

$86\left|n^{\circ} 7\right|$ doxa.comunicación
} 
participan el Grupo Planeta, Grupo Joly, Grupo Promotor Salmantino (La Gaceta Regional de Salamanca), Heraldo de Aragón, Grupo Serra (Última Hora), La Información (Diario de Navarra) y La Voz de Galicia, es decir, grupos regionales que gestionan diarios de pago, junto a Planeta.

Cuenta con ediciones en Madrid, Barcelona, Valencia, A Coruña, Aragón, Bilbao, Cádiz, Castellón, Lleida, Málaga, Mallorca, Pamplona, La Rioja, Sevilla y Vigo.

Según los datos del Tercer Acumulado Móvil del Estudio General de Medios de 2007, ADN cuenta con 1.417.000 lectores diarios. Estas cifras corresponden a un 9,05\% de los lectores totales de la prensa diaria en el país y un 18,64\% de los cuatro principales gratuitos.

\section{Metodología}

Como ya se ha comentado, el objetivo de este trabajo es analizar comparativamente la oferta de los cuatro principales diarios gratuitos en España en sus ediciones para Barcelona.

El análisis que se va a llevar a cabo será esencialmente cuantitativo y se centrará en el formato, destacando los aspectos que son objetivables y mesurables, frente a la subjetividad que podría llevarnos un estudio sobre la orientación de las informaciones insertadas. Como señala Krippendorff (1990), los datos proporcionados por el análisis de contenido permiten al investigador realizar inferencias reproducibles y válidas que pueden aplicarse en relación con su contexto y justificarse en función de éste.

Por su parte, Holsti (1968) señala que el análisis de contenido es un procedimiento que permite analizar y cuantificar los materiales de la comunicación; puede analizarse con detalle y profundidad el contenido de cualquier comunicación (código lingüístico oral, icónico, gestual, gestual signado...) sea cual fuere el número de personas implicadas en la comunicación (una, diálogo, grupo restringido, comunicación de masas...), pudiendo emplear cualquier instrumento de compendio de datos (agendas, diarios, cartas, cuestionarios, encuestas, tests proyectivos, libros, anuncios, entrevistas, radio, televisión, etc.).

Asimismo, Krippendorff (1990: 28) describe el análisis de contenido como "la técnica destinada a formular, a partir de ciertos datos, inferencias reproducibles y válidas que puedan aplicarse a un contexto".

Se trata, según Bernard Berelson (1971), de una técnica para estudiar y analizar la información de una manera objetiva, sistemática y cuantitativa. "Esto ocurre por el descubrimiento de los contenidos y de las estructuras que confirman (o no) lo que se quiere demostrar a propósito de los mensajes, o por el esclare- 
cimiento de los elementos significativos susceptibles de conducir a una descripción de mecanismos de los que a priori no detenemos la comprensión" (Bardin 1995: 29)

En consecuencia, este enfoque se inserta tanto dentro del Content analysis de Estados Unidos, entendido, según Berelson, como "una técnica de investigación para la descripción objetiva, sistemática y cuantitativa del contenido manifiesto de las comunicaciones" (1986: 13), como en la tradición europea de estudios de contenido que toma como elementos de análisis la presentación de los mensajes, la valoración, emplazamiento, titulación y compaginación como categorías de medición, los elementos estructurales, la morfología del medio y las unidades redaccionales (Krippendorff 1990).

En este sentido, la "morfología" de cada una de las cuatro cabeceras la desglosaremos, por un lado, en las cuestiones técnicas relacionadas con el diseño: dimensiones, estructura general de la maqueta y de la página, estructura de la portada, recursos tipográficos, utilización de la imagen (fotografía, ilustración e infografía) y empleo del color; y, por otro lado, en aspectos que podríamos denominar "editoriales", que serían la aplicación concreta de esas propuestas "morfológicas" durante la semana objeto de estudio.

Las principales cuestiones que hemos denominado de decisión editorial son qué secciones tiene cada uno de los diarios, en qué orden están situadas; qué aspectos las diferencian, cuántas noticias hay en cada página; qué elementos de titulación se emplean y cuáles son sus características, y qué tipo, de qué tamaño y dónde se encuentran las ilustraciones. Por el enfoque que hemos elegido no nos ha parecido relevante distinguir entre información y opinión, por lo que hemos llamado a las unidades distintas de texto no publicitario "unidades" (tanto de información como de opinión).

La herramienta básica de trabajo ha sido la ficha que se reproduce a continuación, que ha permitido recabar datos diarios de cada una de las cuatro cabeceras durante los cinco días que se establecieron como período de análisis para este estudio.

Tabla I. Ficha de análisis

\begin{tabular}{|ll|}
\hline 1. Generalidades & Periódico: \\
\hline & Fecha: \\
\hline & No de páginas \\
\hline & No columnas pág. estándar \\
\hline & No de secciones \\
\hline 2. Uso del color & Páginas a color \\
\hline
\end{tabular}




\begin{tabular}{|c|c|}
\hline \multirow[t]{10}{*}{ 3. Cuerpo de texto } & No unidades texto \\
\hline & Promedio unidades página \\
\hline & Unidades $>1$ página \\
\hline & Unidades a toda página \\
\hline & Unidades $>1 / 2$ página \\
\hline & Unidades a $1 / 2$ página \\
\hline & Unidades de $1 / 4$ página \\
\hline & Unidades de $1 / 6$ página \\
\hline & Unidades de 1/12 página \\
\hline & Breves \\
\hline \multirow[t]{7}{*}{ 4. Elementos de titulación } & Titulares $>1$ página \\
\hline & Titulares a página entera \\
\hline & Titulares a 5 columnas \\
\hline & Titulares a 4 columnas \\
\hline & Titulares a 3 columnas \\
\hline & Titulares a 2 columnas \\
\hline & Titulares a 1 columna \\
\hline \multirow[t]{10}{*}{ 5. Imagen } & No de fotografías \\
\hline & $\mathrm{N}^{o}$ fotografías a color \\
\hline & Fotografías > 1 página \\
\hline & Fotografías de 1 página \\
\hline & Fotografías $>1 / 2$ página \\
\hline & Fotografías de $1 / 2$ página \\
\hline & Fotografías de $1 / 4$ de página \\
\hline & Fotografías de $1 / 6$ de página \\
\hline & Fotografías de 1/12 página \\
\hline & Fotografías $<1 / 12$ de página \\
\hline
\end{tabular}




\begin{tabular}{|ll|}
\hline & No de infografías \\
\hline & Infografías a color \\
\hline & Infografías > 1 página \\
\hline & Infografías de 1 página \\
\hline & Infografías $>1 / 2$ página \\
\hline & Infografías de 1/2 página \\
\hline & Infografías de 1/4 de página \\
\hline & Infografías de 1/6 de página \\
\hline & Infografías de 1/12 de página \\
\hline & Infografías < 1/8 d12 página \\
\hline & Ilustración artística \\
\hline & Ilustración humorística \\
\hline Barcelona \\
\hline España \\
Mundo \\
Oámero de páginas de \\
Oariables, según cada \\
publicación)
\end{tabular}

$90\left|n^{\circ} 7\right|$ doxa.comunicación 


\begin{tabular}{|l|}
\hline No de fotografías $<1 / 4$ de $\mathrm{p}$. \\
\hline No de infografías \\
\hline No de infografías a 1 página \\
\hline No de infografías a 1/2 página \\
\hline No de infografías a 1/4 de página \\
\hline No de infografías $<1 / 4$ de p. \\
\hline Titulares a toda página \\
\hline Titulares de 5 columnas \\
\hline Titulares de 4 columnas \\
\hline Titulares de 3 columnas \\
\hline Titulares de 2 columnas \\
\hline Titulares de 1 columna \\
\hline
\end{tabular}

Fuente: Elaboración propia

\section{Planteamiento del diseño}

Los diarios recurren tanto al fondo (el lenguaje verbal escrito) como a la forma (selección y combinación de los elementos gráficos) para comunicarse con sus lectores. En el caso de la prensa gratuita, el contexto en el que se consume y su financiación condicionan de raíz su diseño. Por una parte, tiene que posibilitar una lectura fragmentada, lo más rápida y visual posible, de manera que en el trayecto de casa al trabajo la persona pueda conocer los principales mensajes que el periódico quiere comunicarle (supuestamente, los temas más importantes de su interés). Por ello, las unidades tienen que ser forzosamente sintéticas, y los puntos a destacar han de quedar claros a simple vista. La visualidad se vuelve entonces un elemento clave, apoyada en dos niveles de lectura, el uso del color, los recursos gráficos y tipográficos y todo lo que redunde en un mayor dinamismo en la presentación de los contenidos.

Por otro lado, su única fuente de financiación (la publicidad) casi les obliga a dar un trato privilegiado a los anuncios (en comparación con la prensa tradicional), en el que la jerarquía entre unidades periodísticas y publicitarias a menudo no llega a quedar clara.

Se da incluso el caso de portadas-anuncio en la página 1, quedando la portada "de verdad”, en la página 3 , algo impensable y quizás ofensivo en un periódico de pago. 
Sobre todas estas premisas, los cuatro periódicos gratuitos construyeron sus diseños, algunos de los cuales han experimentado modificaciones en el transcurso de los años. El que ofrece actualmente 20 Minutos lo implantó David Velasco en 2004; el de Metro es creación de Ole Munk; Qué! imita ostensiblemente el periódico insignia de esta corporación, el deportivo Marca, cuyo equipo de diseño dirige José Juan Gámez, y, $A D N$ está diseñado por Cases i Associats, un estudio de diseño responsable de la renovación de numerosos medios españoles e internacionales.

\section{Formato y número de páginas}

Las cuatro cabeceras sujeto de este estudio tienen el mismo formato: el tabloide estándar ( 289 x $410 \mathrm{~mm})$. Ello tiene dos grandes ventajas: por un lado, son las dimensiones de prácticamente toda la prensa generalista diaria en España, por lo que los lectores están habituados a ellas, y, por otro, la mayoría de rotativas de impresión optimizan su funcionamiento con este formato, lo que supone un ahorro de costes. En este sentido, los gratuitos no han supuesto una novedad, aunque sí que han impulsado, parcialmente, a otros medios de pago, de otros formatos, a pasarse al tabloide estándar (por ejemplo, La Vanguardia, que lo adoptó en octubre de 2007).

En cuanto al número de páginas, se trata, por su propia naturaleza, de periódicos poco extensos en comparación con los tradicionales: todos ellos ofrecen entre 28 y 32 páginas, según el día, aunque ocasionalmente 20 Minutos y Qué! pueden tener 24 páginas.

\section{Maqueta y estructura de la página}

Es quizás en el diseño de las páginas donde se aprecian mejor las diferencias entre uno y otro periódico y entre los gratuitos y la prensa tradicional. Todos ellos comparten las características generales mencionados en el apartado 4, pero las llevan a la práctica de distinta manera.

Igual que en lo referente al formato y número de páginas, la maqueta de estas cuatro cabeceras coincide en el número de columnas, seis, lo que las diferencia de los periódicos tradicionales, que en su mayoría manchan a cinco columnas. Son una excepción las portadas, que en general tienen menos columnas y de ancho variable, a las que dedicaremos un apartado específico.

En sus páginas, 20 Minutos trata de que el lector se pueda crear un mapa visual claro, estableciendo una clara diferenciación entre las unidades mediante la jerarquización de los titulares y el estilo (negrita versus redonda), situando el texto sobre pastillas de colores o dentro de recuadros y separándolas con filetes, por 
ejemplo, y con la disposición de los blancos. Aparece en varias páginas bajo la cabecera (siempre de color) un friso azul (el color corporativo), donde se sitúan noticias breves. Sus módulos de composición son variados, de modo que no se puede establecer claramente su unidad base, pues tanto ocupan una parte de una o más columnas, como llegan a ser en pistola. Sin embargo, las seis columnas son claramente perceptibles en prácticamente todas las páginas y, en general, hace una buena optimización del espacio. Sólo los artículos de opinión se maquetan a menos columnas y más anchas, como hacen la mayoría de periódicos de pago.

Metro Directo, por su parte, también se apunta a las cabeceras de color, en forma de gran pastilla con las letras perforadas en el caso de las aperturas de sección. La fragmentación visual de las unidades se consigue gracias, sobre todo, a un acertado uso de los blancos y la tipografía, más que a otros elementos extratextuales como serían recuadros o filetes. Estos últimos, aunque abundantes tanto verticales como horizontales, son muy discretos. Metro ha intentado aprovechar nuevos espacios en la página, como el blanco que queda sobre la cabecera, aunque las noticias breves que se colocan en esta franja en casi todas las páginas pasan a menudo inadvertidas, pues la letra es de tamaño muy pequeño y la vista está acostumbrada a buscar en primer lugar los grandes titulares y luego ver el cuerpo de estas noticias. Casi hay que hacer un esfuerzo consciente para dirigir la vista hasta la posición de estas pequeñas unidades. El módulo de composición de media columna (un doceavo de página) parece ser la unidad básica. El resultado de todo ello es que el lector percibe un diseño claro y equilibrado, sin que por ello se pierda la posibilidad de una lectura rápida.

La tercera de las cabeceras, Qué!, es quizá la que presenta un aspecto menos ordenado, con una jerarquización poco clara de las unidades, con una gran fragmentación en la que un mismo tema puede llegar a tener quince o más unidades. Por otro lado, el uso de elementos de separación como recuadros, pastillas y titulares llamativos hace que, a veces, cueste agrupar las unidades que forman parte de un mismo tema. El módulo base queda tan desdibujado que en ocasiones llega a hacerse imperceptible y se desdibuja la estructura de seis columnas. A diferencia de los otros tres, el nombre de la sección que aparece en la cabecera de cada página es gris, y la nota de color la pone el nombre del periódico, Qué!, en su rojo característico.

Finalmente, $A D N$ estructura sus páginas estándar bajo una pequeña cabecera de color y establece una clara jerarquía de unidades mediante el uso de titulares de distinto tamaño y extensiones acorde con la importancia que se quiere dar a la información. Por otro lado, en comparación con los otros tres, no abundan los elementos gráficos no textuales, como filetes, recuadros (estos se reservan para las foto-noticias) y topos. Sin embargo, se consigue perfectamente diferenciar los bloques mediante un estudiado uso de los blancos y los medianiles. En las páginas de apertura de sección encontramos una cabecera de color y unos elementos de titulación de mayor tamaño (en algún caso, también en color). Igual que Metro, su unidad 
modular básica es la media columna y sus múltiplos. En definitiva, el diseño de Cases i Associats es el que produce una impresión más limpia y armoniosa de los cuatro, que pone en entredicho el presupuesto de que una mayor fragmentación gráfica de la información facilita una lectura más rápida.

\section{Color}

La utilización del color es una de las características diferenciales del formato de la prensa gratuita. Su introducción a todos los niveles, desde las imágenes hasta los filetes, se hace absolutamente evidente en las cuatro publicaciones, pues se ha convertido en un recurso visual que acerca, de algún modo, la prensa escrita a la televisión e Internet, que ofrecen todos sus contenidos en color.

El decano de los cuatro, 20 Minutos, utiliza el color en las cabeceras y elementos de titulación, ya sea directamente en la tipografía, ya sea poniendo pastillas de fondo con las letras en negativo o en negro. Ocasionalmente aparece alguna página en blanco y negro, pero nunca más de cuatro. Aparte de esas excepciones, todas las imágenes, gráficos e ilustraciones son a color. El color de las cabeceras también sirve para diferenciar las secciones: azul para la información local (Barcelona y Cataluña), Zona 20 (página de los lectores), Actualidad (Sociedad) y la tecnología (DosPuntoCero); verde para Deportes, y verde oliva y un tono rojizo para La Revista (Cultura, Ocio, Gente, Televisión). Dentro de esta última, los distintos apartados también tienen su código cromático: tono rojizo para Cultura y tendencias, verde oliva para Ocio y espectáculos, azul para información de Internet, rosa para Gente y naranja para Televisión. Junto a todas las cabeceras aparece la mancha azul con el logo del periódico.

Por su parte, Metro también publica prácticamente todas sus páginas en color (en la semana objeto de análisis sólo hemos encontrado una página en blanco y negro), utilizándolo en cabeceras, elementos de titulación, fotografías, gráficos e ilustraciones. Aplicado a las cabeceras, le permite agrupar varias secciones en amplios apartados: Cataluña, España, Mundo y Economía, en azul; cartas de los lectores y Servicios, en verde; naranja para los Deportes; lila para secciones variadas como Decoración o Entrevistas, y rosa para las páginas de famosos, Ocio y Televisión.

Qué! es seguramente el gratuito que mancha más y más vivamente en color de los cuatro y no deja ninguna página en blanco y negro. Lo aplica generosamente en tonos de intensidad variada en elementos de titulación, pastillas, filetes y recuadros, así como en fotografías, gráficos e ilustraciones. Curiosamente, sin embargo, las cabeceras de las páginas son en gris, y sólo su distintivo logo en rojo aporta un toque vivo de color. Por secciones, el azul (en filetes, pastillas y titulares) identifica las páginas de Interés general, Barcelona,

$94\left|n^{\circ} 7\right|$ doxa.comunicación 
Emergencias, Deportes y Servicios; el rojo lo encontramos en Al día (sociedad, internacional, política...); el naranja distingue La Vida (cultura y tendencias) y Televisión, y para Gente se ha optado por el rosa.

Por último, $A D N$ comparte con los otros tres un uso profuso del color en todas sus páginas y desde la titulación hasta las llamadas para consultar su página web. Como en los anteriores casos, cada sección o secciones tiene su color, en este caso, azul para Barcelona, Política, Internacional, Economía y las cartas de los lectores; naranja para La Vida (sociedad, ciencia...); verde para los Deportes; rojo para Cultura y Ocio, El Bulevar (famosos) y Televisión y Radio. Curiosamente es el único de los tres que no utiliza el rosa en ninguna de las secciones.

\section{Imagen}

Indisolublemente vinculada al uso del color en este tipo de publicaciones, el tratamiento de la imagen es uno de los aspectos más novedosos en este formato de prensa diaria. En términos generales podríamos decir que su tratamiento se ha acercado más al que hacen las revistas, con abundancia de recortes, montajes, superposiciones, diversidad de tamaños y de ubicación, etc. Con ello se busca introducir mayor dinamismo a las páginas, en un intento de acercarse a los hábitos de consumo de televisión y de Internet. En general todas las imágenes son en color, excepto en las escasas páginas en blanco y negro o cuando la propia fotografía fue tomada así.

Hay que reconocer que en cuanto al tratamiento de la imagen se refiere Qué! presenta el aspecto más innovador de los cuatro, mientras que las otras cabeceras son menos arriesgadas, sobre todo Metro y ADN.

\subsection{Fotografía}

Al hacer el recuento del número de fotografías, se observa que 20 Minutos, Metro y ADN colocan un promedio similar: 88,6, 89,2 y 84,6, mientras que Qué! ofrece 122,4. En cuanto al tamaño, en general son bastante pequeñas. Por ejemplo, más de tres cuartas partes $(77,8 \%)$ de las fotografías de 20 Minutos son menores a media columna, mientras que las imágenes de un cuarto o media página representan sólo el $2,6 \%$, sin que aparezcan nunca fotografías mayores. Porcentajes similares encontramos en Metro Directo (80,7 menores a media columna y 2,4 de un cuarto o media página) y fotografías algo mayores en ADN (72,5\% menores a media columna y 4,9\% iguales o superiores a un cuarto de página). En cambio, Qué!, al introducir más cantidad de imágenes, se ve obligada a reducir su tamaño medio, con lo que el 81,3\% de ellas son menores al espacio de media columna, frente a tan sólo el 0,7 igual o superior a un cuarto de página. El resto de imágenes tienen un tamaño intermedio. 
En cuanto a la manipulación, $A D N$ trabaja habitualmente con formatos regulares (rectangulares, horizontales y verticales), ofreciendo así la imagen más clásica. Metro Directo, sin ser muy atrevido en este sentido, introduce algunos silueteados y montajes, sobre todo en las páginas de deportes, ocio, televisión, famosos y secciones especiales. Un paso más allá va 20 Minutos, que ya juega más con el tamaño y la forma de las imágenes, aunque, como se ha dicho, la cabecera que lleva estas posibilidades hasta el extremo es Qué!, que sin llegar a la corriente de tratamiento de imagen sensacionalista, es el que más se acerca a la estética de las revistas.

Antes de cerrar este punto, cabe mencionar que todos ellos presentan a algunos de sus redactores con una pequeña fotografía recortada al lado de la firma.

Tabla II. La fotografía en la prensa gratuita

\begin{tabular}{|l|c|c|c|c|c|c|c|c|}
\hline FOTOGRAFÍA & \multicolumn{2}{|c|}{20 Minutos } & \multicolumn{2}{c|}{ Metro Directo } & \multicolumn{2}{c|}{ Qué! } & \multicolumn{2}{c|}{ ADN } \\
\hline Ítem & No & $\%$ & No & $\%$ & No & $\%$ & No & $\%$ \\
\hline No de fotografías & 88,6 & & 89,2 & & 122,4 & & 86,4 & \\
\hline No de fotografías a color & 84,4 & $95,1 \%$ & 88,8 & $99,6 \%$ & 121,4 & $99,2 \%$ & 78 & $90,3 \%$ \\
\hline Fotografías > 1 página & 0 & & 0 & & 0 & & 0 & \\
\hline Fotografías de 1 página & 0 & & 0 & & 0 & & 0 & \\
\hline Fotografías > 1/2 página & 0 & & 0 & & 0 & & 0 & \\
\hline Fotografías de 1/2 página & 0,2 & $0,2 \%$ & 0,4 & $0,4 \%$ & 0,2 & $0,1 \%$ & 1,8 & $2,1 \%$ \\
\hline Fotografías de 1/4 de pág. & 2 & $2,4 \%$ & 1,8 & $2,0 \%$ & 0,6 & $0,6 \%$ & 2,4 & $2,8 \%$ \\
\hline Fotografías de 1/6 de pág. & 7,4 & $8,4 \%$ & 6,2 & $7,0 \%$ & 5,2 & $4,6 \%$ & 9,8 & $11,3 \%$ \\
\hline Fotografías de 1/12 de pág. & 9,8 & $11,2 \%$ & 8,8 & $9,9 \%$ & 16 & $13,4 \%$ & 9,8 & $11,3 \%$ \\
\hline Fotografías < 1/12 de pág. & 69,2 & $77,8 \%$ & 72 & $80,7 \%$ & 100,4 & $81,3 \%$ & 62,6 & $72,5 \%$ \\
\hline
\end{tabular}

Fuente: Elaboración propia

\subsection{Infografía}

Aunque algunos analistas resaltan el grafismo como una de las características de este tipo de prensa porque la acerca a la animación digital y de televisión, la realidad indica que no es uno de sus puntos fuertes, quizá porque tener un buen equipo de infografistas tiene un coste elevado. Básicamente encontramos

$96 \mid n^{\circ} 7$ | doxa.comunicación 
ilustraciones generadas por ordenador en la información meteorológica y en los signos zodiacales del horóscopo.

20 Minutos presenta la tendencia de la bolsa y los valores al alza y a la baja en forma de gráfico, así como, ocasionalmente, alguna encuesta realizada entre sus lectores. Además, de vez en cuando introduce en el lugar de la capitular algún símbolo como el de la lotería o la mano de búsqueda de las páginas web. Los juegos (sudoku y autodefinido) en la página de Servicios de Metro Directo son lo más asimilable a infográficos que presenta este periódico, más allá de los ya mencionados de meteorología y horóscopos. Por su parte, Qué! es el que menos elementos de infografía introduce, pero lo compensa con abundantes tablas de datos y con su tratamiento de la imagen. Por último, $A D N$, es el que menos infográficos introduce, con algún pequeño símbolo en las páginas de economía (flechas para indicar tendencias al alza o a la baja) y de vez en cuando algún gráfico de porciones para explicar alguna encuesta.

\subsection{Ilustración}

Tampoco éste es un punto fuerte de los cuatro principales gratuitos españoles. Mientras que todos introducen entre una y tres viñetas cómicas (según el periódico y el día, siendo $A D N$ el qué con mayor frecuencia ofrece tres), la ilustración artística o decorativa es mucho más escasa. 20 Minutos y Metro incluyen, de media, una diaria, aunque hay días que no ofrecen ninguna y otros días más de una. $A D N$ colocó seis en un solo día (el resto no publicó ninguna), mientras que el diario Qué! varía entre ninguna y cuatro. Por lo general se trata de pequeños dibujos que acompañan a un texto, con una intención básicamente ornamental.

\section{Recursos tipográficos}

Los juegos con distintos tipos de letra y, sobre todo, con distintos tamaños, son otra de las maneras que tienen los periódicos gratuitos de introducir dinamismo en las páginas y hacerlas más ágiles. Todos ellos coinciden con la prensa tradicional en el uso preeminente de dos familias tipográficas, una de palo seco para los elementos de titulación y otra romana para el cuerpo de texto general. Asimismo encontramos en los cuatro rotativos abundantes elementos tipográficos no textuales, como topos, estrellas o filetes y un uso del texto a bandera, infrecuente en el resto de la prensa generalista diaria.

En el caso de 20 Minutos, por ejemplo, el tipo de letra empleado en los bloques de texto general es Utopía de 9 puntos, sobre un interlineado de 10, que se combina con el tipo PoynterAgateOne negrita (en tamaños diversos) condensada para los titulares. Por su parte, Metro creó una variación de Swift (Metro Swift), que 
es con el que compone los textos generales, en un cuerpo de 9 puntos sobre una interlínea también de 10 puntos. Su contrapeso recae en Corpid, utilizado para los elementos de titulación y textos complementarios. Qué! trabaja su texto básico en Nimrod regular de 8,5 puntos, mientras que para los elementos de titulación recurre a Interstate. Por último, $A D N$ contrapone la versión romana de Benton Modern con Dinot, aunque éste no se emplea propiamente para los titulares, sino para textos de apoyo, ladillos, subtítulos, antetítulos y similares.

\subsection{Elementos de titulación}

Sin entrar a analizar su composición en detalle, sí que parece importante reseñar brevemente qué elementos de titulación emplea cada uno de los cuatro medios analizados y la extensión de sus titulares. Dejaremos las cabeceras de página y de apertura para cuando tratemos las secciones.

Empezando por orden de antigüedad, 20 Minutos redacta titulares (en negro, en color y en negativo sobre pastillas de color) y en las noticias más extensas también subtítulos que prácticamente son entradillas. De hecho, en las noticias más breves, en las que no tendría cabida un subtítulo, a veces se resaltan en negrita las primeras palabras, a modo de entradilla, aunque no parece existir un criterio claro para estos casos. Los ladillos pueden estar en caja alta o caja baja, en tipo de palo seco o con serifa e incluso en color. Todas las noticias están debidamente identificadas con su pie, diferenciado tipográficamente con claridad, aunque a veces contribuyen un poco a producir la sensación de página sobrecargada. Finalmente, sólo encontramos antetítulo (que puede ser en color) o encabezamiento en aquéllas noticias de mayor extensión, entre una y tres diarias. En cuanto a su ancho, dos tercios de los titulares $(65,1 \%)$ son a una columna, un $21,9 \%$ a dos, y el resto a tres o más (sólo un $0,2 \%$ de los titulares son a página entera).

Por su parte, en Metro Directo, la jerarquía de elementos de titulación está bastante bien resuelta, con titulares, subtítulos y, en las noticias más amplias, entradilla. Sin embargo, han optado por no incluir antetítulo, quizá para no fragmentar más la información y en las unidades más breves, a veces ni siquiera existe un título. Tampoco encontramos ladillos propiamente dichos; cuando quieren introducir una pausa visual dentro de un texto, dejan una línea en blanco y el siguiente párrafo empieza con dos o tres palabras en caja alta, de palo seco, negrita. Cabe destacar que las unidades que no llevan entradilla ni subtítulo suelen comenzar con un epígrafe en color que adelanta el tema de que se trata: Movilidad, Maltratos, Cine, Política, etc. Todos los elementos de titulación pueden ser ocasionalmente en color, bien sea perforados sobre una pastilla, bien sea directamente. La lectura de los pies de foto es clara y con suficiente espacio blanco para no agobiar. Su estructura de composición favorece las unidades un poco más hori- 
zontales que 20 Minutos, incluso las breves, por lo que encontramos menos titulares a una columna (sólo el $50,6 \%$ ), frente al $27 \%$ a dos, el $5 \%$ a tres, casi el $10 \%$ a cuatro columnas y un $7,7 \%$ de cinco columnas o a página completa.

Continuando con Qué!, en sus noticias podemos encontrar antetítulo (en caja alta y en color o en negro), título y subtítulo en la mayoría de unidades medianas y extensas. Los pies de foto son discretos y los ladillos están ausentes (pocos textos tienen la longitud suficiente como para introducirlos y en caso de ampliar o profundizar alguna información se opta directamente por una pieza diferente de texto). Es obligado mencionar que es el gratuito que más profusión de color introduce en los elementos de titulación. Éste es el periódico que más titulares a una columna utiliza (el 70,2\%), aunque si hace falta introduce algún titular a página completa o a cinco columnas $(2 \%)$.

Por último, $A D N$ también emplea uno e incluso dos subtítulos y entradilla en las informaciones más extensas (raramente más de una en cada edición), acompañando y complementando al titular. Lo que no abunda son los ladillos, aunque eso no implica que no se introduzcan; lo que ocurre es que, a veces, un pequeño apunte o información complementaria diferenciada gráficamente ya es una pausa visual suficiente. En cambio, sí abundan los epígrafes en color (el propio de cada sección) que dan alguna orientación sobre la información (Pakistán, La cifra, El apunte, Sanidad, Medio Ambiente, Reportaje, etc.). Aunque la mayoría de sus titulares son, igual que en los otros tres periódicos, a una columna (62\%), encontramos una cuarta parte a dos o tres y un importante $5,8 \%$ a cinco o seis columnas, siendo el que, de media, emplea titulares más largos.

\section{Cuestiones editoriales}

\subsection{Secciones: descripción y orden}

En general, la prensa gratuita diaria en España adolece de un cierto desorden en la organización de las secciones, aunque más acentuado en unos medios que en otros.

20 Minutos mantiene una estructura fija con siete secciones, de las cuales Barcelona (tres o cuatro páginas), Cataluña (una o dos páginas), Actualidad (tres o cuatro páginas), Deportes (de dos a cinco páginas), Zona 20 -cartas de los lectores y opinión- (una o dos páginas) y La Revista (siete u ocho páginas) son fijas. La séptima sección puede ser Salud y belleza (los lunes), Formación y empleo (los martes), DosPuntoCero -tecnología- (los miércoles), Vivienda y hogar (los jueves) o Tutiplán -propuestas de ocio y cultura para el 
fin de semana- (los viernes). La extensión de estas secciones variadas oscila entre una y once páginas, siendo Tutiplán la más extensa. Por otro lado, las páginas de Actualidad y Zona 20 pueden variar su emplazamiento dentro del orden de las secciones, en función de las necesidades del periódico.

En cuanto a colores, Deportes lleva la cabecera verde, La Revista verde y roja (aunque sus sub-secciones incluyen también el rosa para Gente y el naranja para Televisión), y el resto (incluyendo las secciones extra) en azul. Tutiplán rescata el tono rojo de La Revista. Deportes, Zona 20 abren sección con una cabecera distinta, mayor, con texto en negativo sobre una pastilla de color, que luego se convierte en letras de color en el resto de páginas.

Tabla III. Secciones de 20 Minutos

\begin{tabular}{|c|c|c|}
\hline Sección & No Pág. & $\%$ \\
\hline Barcelona & 3,2 & $11,6 \%$ \\
\hline Catalunya & 1,6 & $5,8 \%$ \\
\hline Actualidad & 3,8 & $13,8 \%$ \\
\hline Deportes & 2,8 & $10,2 \%$ \\
\hline Opinión & 1,4 & $5,0 \%$ \\
\hline Vivienda y hogar & 0,6 & $1,9 \%$ \\
\hline La Revista & 6,6 & $24,2 \%$ \\
\hline Formación y empleo & 1,0 & $3,7 \%$ \\
\hline Salud y belleza & 0,2 & $0,7 \%$ \\
\hline Dos Punto Cero & 0,4 & $1,7 \%$ \\
\hline Tutiplán & 2,2 & $7,1 \%$ \\
\hline
\end{tabular}

Fuente: Elaboración propia

Por su parte, Metro Directo también empieza con la información de proximidad (Cataluña, de dos a cuatro páginas, y España, una o dos páginas), para seguir con Mundo, Economía, Opinión y Servicios, con una página cada una. Cierran las secciones fijas los Deportes (entre una y doce páginas), el ocio (dos o tres páginas bajo la cabecera de Actualidad) y la programación de televisión. En las secciones variables encontramos gran variedad de cabeceras y extensiones: Entrevista (una página, los martes), Decoración (una página, los jueves), Noticias -de medio ambiente, actualidad... - (una página, los jueves), algún Especial (por ejemplo, 
cuatro páginas dedicadas a regalos de Navidad), Gente (una página los martes), Metro-On -videojuegos y música- (ocho páginas los miércoles) o una página extra de Actualidad insertada los martes entre España y Mundo. Por último, hay que destacar que los lunes la información deportiva (incluyendo el mundo del motor) se publica en un suplemento encartado en el centro, con portada y numeración propia.

Como en los otros tres diarios, los colores de las cabeceras agrupan diversos bloques de secciones: Cataluña, España, Mundo y Economía en azul; Cartas de los lectores, Servicios y Music-On en verde; naranja para los Deportes; rosa para Ocio, Televisión, Gente y Especiales, y lila para Entrevista, Decoración y Noticias. La primera página de las cuatro partes de color fijas se abre con una banda ancha del mismo color, con el texto perforado en letras grandes (en el caso del bloque azul, le colocan el epígrafe general Noticias). En realidad, esta diversidad y variación diaria de secciones crea una sensación de indefinición, de improvisación, que hace que el lector no acabe de tener la impresión de conocer con seguridad este periódico.

Tabla IV. Secciones de Metro Directo

\begin{tabular}{|l|c|c|}
\hline Sección & No Pág. & $\%$ \\
\hline Cataluña & 3,2 & 11,9 \\
\hline España & 1,6 & $5,9 \%$ \\
\hline Actualidad (Sociedad...) & 0,2 & $0,7 \%$ \\
\hline Mundo & 1,0 & $3,7 \%$ \\
\hline Economía & 1,0 & $3,7 \%$ \\
\hline Opinión & 1,0 & $3,7 \%$ \\
\hline Servicios & 1,0 & $3,7 \%$ \\
\hline Especiales & 0,8 & $3,0 \%$ \\
\hline Deportes+Motor & 4,6 & $17,0 \%$ \\
\hline Entrevista & 0,2 & $0,7 \%$ \\
\hline Actualidad (Ocio) & 4,6 & $17,0 \%$ \\
\hline Televisión & 1,2 & $4,4 \%$ \\
\hline Gente & 0,2 & $0,7 \%$ \\
\hline
\end{tabular}




\begin{tabular}{|l|l|l|}
\hline Metro-On & 1,6 & $5,9 \%$ \\
\hline Decoración & 0,2 & $0,7 \%$ \\
\hline Noticias & 0,2 & $0,7 \%$ \\
\hline
\end{tabular}

Fuente: Elaboración propia

Qué! empieza siempre con las secciones Interés general (la selección de temas del día que hace la redacción, por lo general no noticias de las últimas horas) y Barcelona, con dos y tres/cuatro páginas respectivamente. A continuación podemos encontrar las cartas de los lectores (que aparecen sólo tres días a la semana) y/o Emergencias (sucesos), con una página cada una. Le siguen la información de sociedad, bajo el epígrafe Al día (entre dos y cinco páginas), los Deportes (de una a cuatro páginas), La Vida (entre dos y cuatro páginas dedicadas a ciencia, cultura y temas bastante variados), Gente (una página), Televisión (dos o tres páginas), Servicios (una página más) y cierra Qué!última, la contraportada. Los jueves, las secciones de siempre son, en general, algo más breves, pues se dedican ocho páginas a la información inmobiliaria (Qué!casas); el martes es la sección Qué!empleo la que ocupa cuatro páginas, y el viernes la cartelera cinematográfica llena dos páginas. Estas secciones de empleo e inmobiliaria son, de hecho, como suplementos, pues aunque están encartadas en el centro, tienen portada y numeración propia.

Respecto a las cabeceras de las secciones, están en letra gris, aunque acompañadas del logo del periódico en rojo. En la contraportada encontramos el epígrafe en blanco sobre pastilla roja y los viernes la sección La Vida abre con una gran cabecera (Qué bien!) con letras naranjas sobre mancha negra. Lo que confunde un poco en Qué! es la aparición y desaparición de la página de cartas de los lectores, el salto de Emergencias antes y después de Al día o encontrar Gente entre las páginas de La Vida.

Tabla V. Secciones de Qué!

\begin{tabular}{|l|c|c|}
\hline Sección & No Pág. & $\%$ \\
\hline Interés general & 2,0 & $6,7 \%$ \\
\hline Barcelona & 3,2 & $10,7 \%$ \\
\hline Opinión & 0,6 & $2,0 \%$ \\
\hline Emergencias (Sociedad, casos...) & 1,0 & $3,4 \%$ \\
\hline Al día (Sociedad) & 3,8 & $12,7 \%$ \\
\hline Deportes & 2,2 & $7,3 \%$ \\
\hline
\end{tabular}




\begin{tabular}{|l|c|c|}
\hline La Vida (Ciencia, cultura) & 3,2 & $10,7 \%$ \\
\hline Gente & 1,2 & $4,0 \%$ \\
\hline Televisión & 2,2 & $7,4 \%$ \\
\hline Servicios & 1,0 & $3,4 \%$ \\
\hline Qué casas! & 1,6 & $5,5 \%$ \\
\hline Qué bien! (Supl. esp. Fin semana) & 0,0 & $0,0 \%$ \\
\hline Cartelera & 0,4 & $1,3 \%$ \\
\hline Qué! Última & 0,8 & $2,7 \%$ \\
\hline Qué! Empleo & 0,8 & $2,6 \%$ \\
\hline
\end{tabular}

Fuente: Elaboración propia

En el caso de $A D N$, las secciones son doce o trece, según si hay algún extra, pero mantienen un orden estable. Las fijas son: en el primer bloque, en azul, La segunda (un sumario que sólo tiene entidad propia en este diario), Barcelona (cuatro o cinco páginas), Política, Internacional y Economía y Xpresate (la página de los lectores), con una página cada una; en el segundo bloque, en color naranja, se publica La vida (entre dos y cuatro páginas); en tercer lugar, en verde, Deportes (de dos a seis páginas), y por último Cultura y Ocio (dos o tres páginas), El Bulevar (una página) y TV y Radio (dos o tres páginas), todos con cabeceras rojas. Los martes, miércoles y jueves, la doble página central suele estar ocupada por un monográfico (por ejemplo, una exposición sobre Charles Chaplin o sugerencias para regalos de Navidad) llamado Las dobles, que presenta una maquetación totalmente distinta al resto del periódico. Finalmente, los viernes, hay una macro-sección llamada Weekend, con propuestas para el fin de semana, en la que pasan a integrarse Cultura y Ocio y El Bulevar.

Tabla VI. Secciones de ADN

\begin{tabular}{|l|c|c|}
\hline Sección & No Pág. & $\%$ \\
\hline La Segunda & 1,0 & $3,3 \%$ \\
\hline Barcelona & 4,6 & $15,1 \%$ \\
\hline Política & 1,0 & $3,3 \%$ \\
\hline Internacional & 1,0 & $3,3 \%$ \\
\hline Economía & 1,0 & $3,3 \%$ \\
\hline
\end{tabular}




\begin{tabular}{|l|c|c|}
\hline Xpresate & 1,0 & $3,3 \%$ \\
\hline La Vida (sociedad, ciencia) & 3,2 & $10,5 \%$ \\
\hline Deportes & 3,0 & $9,9 \%$ \\
\hline Cultura\&Ocio & 2,2 & $7,2 \%$ \\
\hline El Bulevar & 0,8 & $2,6 \%$ \\
\hline Televisión\&Radio/El Zaping & 2,8 & $9,2 \%$ \\
\hline Contraportada & 1,0 & $3,3 \%$ \\
\hline Weekend & 1,8 & $5,9 \%$ \\
\hline Las Dobles & 1,2 & $3,9 \%$ \\
\hline
\end{tabular}

Fuente: Elaboración propia

\subsection{Unidades de redacción: tamaño y número}

Conocer el número y extensión de las unidades nos servirá para comprobar hasta qué punto es real la fragmentación de la redacción. Recordemos que no deben considerase las unidades como noticias, sino como bloques de texto diferenciados gráficamente, con lo que despieces e informaciones complementarias serían ítems distintos de la información a la que acompañen.

El rotativo 20 Minutos ofrece una media de 228,2 unidades diarias (unas 8,45 por página), lo que, considerando la cantidad de publicidad de estos medios, no es nada desdeñable ${ }^{8}$. En cuanto a su extensión, raramente encontramos temas que ocupen más de media página $(1,3 \%)$ frente al $17,9 \%$ de unidades con una extensión entre una y media columna, o el 72,7\% menores a media columna. El resto son ítems medianos, de entre un cuarto y media página.

El diario Metro Directo fracciona sensiblemente menos sus unidades, pero sigue lejos de los ratios por página de los periódicos de pago. Su media de ítems diarios es de 169,8, lo que supone unos 6,29 por página, de los que casi el 2,4\% ocupan más de media página e incluso más de una, mientras que el 16,3\% equivalen a una o media columna y el 71,1\% son breves, unos porcentajes similares a los que arroja 20 Minutos.

En las páginas de Qué! es donde mejor se aprecia la abreviación de las unidades, pues en cada página encontramos, de media, unas diez unidades $(10,1)$, es decir, 273 en todo el periódico. Lógicamente, a la fuerza

8 Como referencia sirva que El País presenta una media de 160 unidades (1,68 por página) y La Vanguardia una media de 290 ítems (3,1 por página).

$104 \mid n^{\circ} 7$ | doxa.comunicación 
tendrán que ser breves: el 78\% ocupan menos de media columna; el 8,7\%, media columna, y un 5,1 el equivalente a una columna. Sólo el 4,9 de unidades tienen una extensión igual o superior a la media página.

$A D N$, como venimos diciendo, es el que más se acerca a la estructura de la prensa convencional, por lo que ofrece menos unidades (153 de media; 5,67 por página) y no tan breves (una cuarta parte -24,8\%- ocupan entre media y una columna, un $62,7 \%$ de breves, ninguna unidad mayor o igual a una página, y un 3,3\% con una extensión superior a la media página).

Tabla VII. Unidades de redacción en los diarios gratuitos

\begin{tabular}{|l|c|c|c|c|c|c|c|c|}
\hline UNIDADES & \multicolumn{2}{|c|}{20 Minutos } & \multicolumn{2}{c|}{ Metro Directo } & \multicolumn{2}{|c|}{ Qué! } & \multicolumn{3}{c|}{ ADN } \\
\hline Ítems & No & $\%$ & $\mathrm{~N}^{\circ}$ & $\%$ & No & $\%$ & No $^{\prime}$ & $\%$ \\
\hline No de unidades & 228,2 & & 169,8 & & 273 & & 126,8 & \\
\hline No de unids. por página & 8,45 & & 6,29 & & 10,1 & & 4,5 & \\
\hline Unidades > 1 página & 0,2 & $0,1 \%$ & 0,4 & $0,2 \%$ & 2,0 & $0,7 \%$ & 0,8 & $0,6 \%$ \\
\hline Unidades a toda página & 0,2 & $0,1 \%$ & 1,2 & $0,7 \%$ & 1,0 & $0,4 \%$ & 1,2 & $0,9 \%$ \\
\hline Unidades > 1/2 página & 2,6 & $1,1 \%$ & 2,4 & $1,4 \%$ & 3,4 & $1,3 \%$ & 4,4 & $3,5 \%$ \\
\hline Unidades a 1/2 página & 5,8 & $2,6 \%$ & 7,0 & $4,1 \%$ & 7,0 & $2,6 \%$ & 7,0 & $5,5 \%$ \\
\hline Unidades de 1/4 página & 12,6 & $5,5 \%$ & 10,4 & $6,1 \%$ & 9,0 & $3,3 \%$ & 7,4 & $5,8 \%$ \\
\hline Unidades de 1/6 página & 14,6 & $6,5 \%$ & 6,8 & $4,0 \%$ & 14,2 & $5,1 \%$ & 13,4 & $10,6 \%$ \\
\hline Unidades de 1/12 pág. & 25,8 & $11,4 \%$ & 20,8 & $12,2 \%$ & 23,6 & $8,7 \%$ & 16,2 & $12,8 \%$ \\
\hline Breves & 166,4 & $72,7 \%$ & 120,8 & $71,1 \%$ & 212,8 & $78,0 \%$ & 76,4 & $60,3 \%$ \\
\hline
\end{tabular}

Fuente: Elaboración propia

\section{Portada}

Un capítulo aparte merecen las portadas, pues tendrían que ser un fiel escaparate de lo que se va a encontrar en el interior, aunque no siempre sea así.

La de 20 Minutos está maquetada a cuatro columnas, más anchas que las del interior, sobre las que se dispone una noticia principal a tres columnas, otra noticia con una imagen grande a dos o tres columnas y varios titulares a una sola columna. De hecho, toda la columna de la izquierda, justo debajo de la cabecera, es una especie de sumario. 
Aparte de la imagen grande, suele haber entre dos y cuatro imágenes pequeñas. El resultado es una cubierta un poco recargada, con bastante información un poco confusa y una media de catorce titulares por portada. La cabecera consiste en su logo perforado en blanco sobre una pastilla azul, debajo del cual, en rojo, figura qué edición local es (Barcelona, en este caso) y ocupa cerca de la cuarta parte superior de la columna derecha.

La cabecera de Metro Directo se extiende en una franja horizontal de un ancho de tres columnas (sobre cinco a que se compone la portada), centrada, con las letras blancas sobre una pastilla verde y una pequeña franja a modo de subtítulo en la que figura la fecha y el lugar de la edición (Cataluña, por ejemplo). La palabra que destaca es Metro, y Directo es apenas visible colocado en vertical entre la r y la o. A ambos lados queda espacio para una pequeño titular con su correspondiente imagen. En conjunto respira bastante mejor que la portada de 20 Minutos, con una media de 8,2 titulares diarios, siempre con una noticia principal con una imagen grande. Sin embargo, la profusión de colores que solemos encontrar en las portadas de Metro parece indicar un interior algo más caótico, que en realidad no se corresponde con lo que encuentran los lectores que lo abren. Es decir, no se ha acabado de lograr una cara que refleje el alma del periódico.

Qué! es, de los cuatro, el que tiene la cabecera más llamativa: unas grandes letras rojas situadas en la parte superior izquierda. Su portada sí que nos da una idea de lo que va a venir, pues en ella ya aparecen los elementos que luego se repetirán en el interior: pastillas de color, recuadros, filetes más anchos y más estrechos, signos tipográficos de gran tamaño y a color (comillas, por ejemplo) una profusión de fotos pequeñas y ninguna grande y tipografía de muchos tamaños. El resultado es una media de 13,4 unidades y 7,8 fotografías (más o menos el doble que los otros), que parecen un collage.

En el otro extremo, $A D N$, con una cabecera en sobrias letras negras sobre fondo blanco, es el que presenta una portada más clásica. Su cabecera ocupa toda la franja superior, pues al lado del nombre aparece la edición, la fecha y la página electrónica y, a la derecha del todo, parte de alguna imagen de los titulares. Pese a ello, no da poca información: 9,6 informaciones, acompañadas de 3,8 fotografías, de las cuales siempre hay una central grande.

Tabla VIII. Portadas en los diarios gratuitos

\begin{tabular}{|l|c|c|c|c|c|c|c|c|}
\hline Portada & \multicolumn{2}{|c|}{20 Minutos } & \multicolumn{2}{|c|}{ Metro Directo } & \multicolumn{3}{|c|}{ Qué! } & \multicolumn{2}{c|}{ ADN } \\
\hline Ítems & No & $\%$ & No & $\%$ & No & $\%$ & No & $\%$ \\
\hline Núm. de titulares & 14,0 & & 8,2 & & 13,4 & & 9,6 & \\
\hline Núm. de fotografías & 4,0 & & 4,6 & & 7,8 & & 3,8 & \\
\hline Núm. de fotografías a 1 página & 0 & & 0 & & 0 & & 0 & $0,0 \%$ \\
\hline
\end{tabular}




\begin{tabular}{|l|c|c|c|c|c|c|c|c|}
\hline Núm. de fotografías a 1/2 página & 0 & & 0 & & 0 & & 0 & $0,0 \%$ \\
\hline Núm. de fotografías a 1/4 de pág. & 1,0 & $27,3 \%$ & 1 & $21,7 \%$ & 0,2 & $2,0 \%$ & 1 & $26,3 \%$ \\
\hline Núm. de fotografías < 1/4 de pág. & 3,0 & $72,7 \%$ & 3,6 & $78,3 \%$ & 6,4 & $86,0 \%$ & 2,8 & $73,7 \%$ \\
\hline Núm. de infografías & 0 & & 0 & & 0 & & 0 & \\
\hline Núm. de infografías a 1 página & 0 & & 0 & & 0 & & 0 & \\
\hline Núm. de infografías a 1/2 página & 0 & & 0 & & 0 & & 0 & \\
\hline Núm. de infografías a 1/4 de pág. & 0 & & 0 & & 0 & & 0 & \\
\hline Núm. de infografías < 1/4 de pág. & 0 & & 0 & & 1,0 & $0,0 \%$ & 0 & \\
\hline Titulares a toda página & 0 & & 0,8 & $9,8 \%$ & 0 & & 1,2 & $12,5 \%$ \\
\hline Titulares de 5 columnas & 0 & & 0 & & 0 & & 1,0 & $10,4 \%$ \\
\hline Titulares de 4 columnas & 2,0 & $14,3 \%$ & 1,4 & $17,1 \%$ & 0,4 & $3,1 \%$ & 0,8 & $8,3 \%$ \\
\hline Titulares de 3 columnas & 0,4 & $2,8 \%$ & 0,4 & $4,9 \%$ & 1,0 & $7,5 \%$ & 0,2 & $2,1 \%$ \\
\hline Titulares de 2 columnas & 0,8 & $5,8 \%$ & 0,2 & $2,4 \%$ & 1,8 & $13,4 \%$ & 0,4 & $4,2 \%$ \\
\hline Titulares de 1 columna & 10,8 & $77,2 \%$ & 5,4 & $65,9 \%$ & 10,4 & $77,7 \%$ & 6,0 & $62,5 \%$ \\
\hline
\end{tabular}

Fuente: Elaboración propia

\section{Conclusiones}

De todo lo expuesto hasta ahora se puede inferir que con los gratuitos diarios generalistas ha nacido un nuevo modelo de prensa en España, caracterizado, en el plano formal, por un reducido número de páginas en comparación con la prensa de pago, un formato tabloide estándar, una introducción del color que abarca desde la tipografía hasta el fondo de las páginas y un mayor dinamismo en el tratamiento de la imagen, con abundantes recortes y montajes. En consecuencia, se ha acortado la extensión de las unidades de redacción para dar cabida a un mayor número de noticias y se han buscado nuevos espacios para colocarlos; estos ítems más pequeños también han comportado una proliferación de titulares cortos. La infografía y la ilustración, en general, son escasas. Sus portadas suelen presentar una gran cantidad de titulares en comparación con la prensa tradicional, lo que a menudo entra en contradicción con su voluntad de claridad y rapidez de lectura. El orden de las secciones también es una asignatura pendiente, pues no siempre queda clara la estructura ni las agrupaciones. 
El diario Qué! lleva al extremo estas características, tanto para lo positivo como para las consecuencias negativas, mientras que $A D N$ arriesga poco y se mantiene bastante próximo a la estética de los diarios convencionales.

La situación, pues, parece indicar que, pese a que los gratuitos son un fenómeno consolidado en España, su definición formal todavía no lo está tanto. ¿Van a mantenerse con éxito con sus formatos actuales? ¿O bien van a tender, como está pasando con la prensa de pago, a acercar sus características hacia un modelo similar? Faltan todavía unos años para observar su evolución.

\section{Referencias bibliográficas}

Arroyo, M. (2006): “Prensa gratuita: ¿un nuevo modelo informativo?”, Prensa y Periodismo Especializado 3, vol. 2, pp. 147-156. Ballesteros, C. (2004): “¿Quién teme a la prensa gratuita?”, Cuadernos de Periodistas, nº 1, pp. 30-38.

Bardin, L. (1995): Análise de conteúdo, Lisboa: Edições 70.

Berelson, B. (1971): Content analisis in communication research, Nueva York: Hafner.

Berelson, B. (1986): Análisis de Contenido, Madrid: Akal/Universitaria.

Blázquez, P. (2007): “España lidera el 'boom’ de la prensa gratuita”, Capital, no 87.

De la Serna, V. (2004): “Ni tanto, ni tan calvo", Cuadernos de Periodistas, nº 1, pp. 42-43.

Edo, C. (2005): "El éxito de los gratuitos hace más visible la crisis de la prensa diaria de pago", Estudios sobre el mensaje periodístico, $\mathrm{n}^{\circ} 11, \mathrm{pp} .23-44$.

Escolar, A. (2004): “Leer o no leer, ésa es la cuestión”, Cuadernos de Periodistas, n 1. 39-41.

Holsti, Ole R (1968): “Content analysis”, en Lindzey, G. Y Aronson, E.: The handbook of social Psychology, vol. 2, Research Methods, Addison-Wesley, Reading, Mass.

Holsti, Ole R. (1969): Content Análisis for the Social Sciences and Humanities, Massachussets: Addison-Wesley.

Kripendorff, K. (1990): Metodología del análisis de contenido. Teoría y práctica, Barcelona: Paidós Comunicación.

López Lita, R.; Fernández, F; Durán, A.. (2002) (Eds.): La prensa local y la prensa gratuita, Castellón de la Plana: U. Jaume I.

Nieto, A. (1984): La prensa gratuita, Pamplona: EUNSA.

Sabés, F. (2005): Jóvenes y medios de comunicación en Aragón, Huesca: Milenio.

Sabés, F. (2005): “Jóvenes y medios: encuentro o desencuentro", Cuadernos de Periodistas, no 5.

Sabés, F. (2006): “Crece la prensa gratuita”, Chasqui, no 95, pp. 52-55.

Vinyals, M. (2007): “Radiografía de la prensa gratuita”, Anàlisi, no 35, pp. 239-244.

$108\left|n^{\circ} 7\right|$ doxa.comunicación 